\title{
Tonic vibration reflex in Holmes-Adie syndrome: an electrophysiological study
}

\author{
GIOVAN I ABBRUZZESE, MICHELE A B B R ZZZSE, \\ EMILIO F A A LE, A NDSANDRO RATTO \\ From the Department of Neurology, University of Genoa, Genoa, Italy
}

\begin{abstract}
SUMMARY The pathophysiological mechanisms underlying benign areflexia were studied in six patients with Holmes-Adie syndrome. No impairment of sensory conduction velocity of sural nerve was found. A normal tonic vibration reflex was obtained in all patients. $\mathrm{H}$ reflex was absent in five patients, but responses like $F$ waves were recorded in three subjects. These findings suggest that muscle spindles are not affected and that spinal motoneurone excitability is normal.
\end{abstract}

In the Holmes-Adie syndrome a marked decrease or loss of knee and ankle tendon jerks is associated with "pupillotonia," a peculiar pupillary dysfunction (Holmes, 1931; Adie, 1932).

Clinical (Cameron, 1959), pathological (Harriman and Garland, 1968), and pharmacological (Russell, 1956) studies have shown the relevance of a parasympathetic denervation, resulting from a lesion in or peripheral to the ciliary ganglion, in the pathogenesis of the pupillary abnormality.

On the contrary, the definite cause of tendon areflexia is still not fully understood, although several hypotheses have been reported pointing to a spinal synaptic pathology (Hardin and Gay, 1965; McComas and Payan, 1966; Levy, 1967), an impairment of motoneuronal excitability (Vanasse et al., 1974), or a degeneration of excitatory interncurones (Hardin and Gay, 1965.)

The aim of the present investigation was to carry out a further analysis of possible pathophysiological mechanisms underlying benign areflexia. Therefore, in addition to determination of sural nerve conduction velocity and monosynaptic ( $T$ and $H$ ) reflex study, the tonic vibration reflex (TVR) (Hagbarth and Eklund, 1966) of triceps surae was studied to test the possibility of a muscle spindle dysfunction, which has not been completely ruled out as a cause of the areflexia (Harriman and Garland, 1968).

Address for reprint requests: Dr G. Abbruzzese, Clinica Neurologica, Via De Toni 5, I 16132 Genova, Italy.

Accepted 17 April, 1979

\section{Patients and methods}

Six cases of the Holmes-Adie syndrome, one man and five wcmen aged $27-66$ (mean 40 ) years, were studied.

All patients presented a typical picture of pupillotonia (unilateral in three cases, bilateral in three cases). Pharmacological tests showed good dilatation of the pupils with mydriatics and constriction with eserine, pointing to the parasympathetic nature of the pupillary dysfunction. Tendon jerks were absent in five cases, and only one patient (case 5) had weak ankle jerks which could be enhanced by the Jendrassik manoeuvre. Serological tests for syphilis as well as routine laboratory tests, EEG, and EMG were negative or normal in all patients.

The following parameters of sensory conduction velocity of the sural nerve were studied according to the method described by Buchthal and Rosenfalck (1966) and Behse and Buchthal (1971): (a) distal conduction velocity, (b) proximal conduction velocity, and (c) peak-to-peak amplitude of the evoked averaged response at the calf. Stimuli were delivered by a stimulation unit (DISA $14 \mathrm{E} \mathrm{11).} \mathrm{Nerve} \mathrm{potentials} \mathrm{were} \mathrm{amplified}$ (bandwidth $50 \mathrm{~Hz}-10 \mathrm{kHz}$ ) by an EMG amplifier (DISA $14 \mathrm{C} \mathrm{12)}$ and averaged by a digital averager (DISA 14 G 01).

The Achilles tendon reflex ( $T$ reflex) was elicited, with the patients in the prone position, by mechanical taps delivered to the Achilles tendon by a hammer that also triggered the oscilloscope (Tektronix $502 \mathrm{~A}$ ). 
Studies of $\mathrm{H}$ reflexes were performed with the patients in the prone position. Electrode positions and stimulation parameters were chosen according to the methodology described by Hugon (1973). When an $H$ reflex was present, the $H / M$ ratio and the recovery cycle were determined.

To elicit a TVR a small cylindrical vibrator (TVR Vibrator, Keydon) was used, secured over the triceps surae belly by rubber bands. Vibration frequency was $100-160 \mathrm{~Hz}$.

Patients were in the prone position with the leg immobilised in a rigid frame. The foot, positioned in about $10^{\circ}$ plantar flexion, was fixed on a metal baseplate which was connected to a force transducer (Grass FT $10 \mathrm{C}$ ). Patients were instructed to exert a weak constant effort in pressing the foot down against the baseplate.

The electromyogram of the triceps surae was recorded by surface electrodes applied $50 \mathrm{~mm}$ apart over the muscle belly and tendon. The electrodes were shielded from the vibrator by an earth lead in order to reduce the electrical artefacts from the vibrator. The recorded amplified EMG potentials and force transduced signals were monitored on the oscilloscope and photographed by a Recordine camera.

The effect of reinforcement on $\mathrm{T}$ and $\mathrm{H}$ reflexes was checked by performing a Jendrassik manoeuvre and/or a mild voluntary contraction of the triceps surae muscle.

\section{Results (Table)}

Both proximal and distal sensory conduction velocity of the sural nerve and the amplitude of the evoked response at the calf were within the normal range in all patients.

The $\mathrm{T}$ reflex was absent in five patients, even during reinforcement manoeuvres. Case 5 showed bilateral presence of $T$ reflexes with normal amplitude, shape, and latency: a clear facilitation was evoked by the Jendrassik manoeuvre and by weak contraction of triceps surae.
A typical $\mathrm{H}$ response could not be obtained in five out of six patients. In three subjects, however, (cases 1, 4, and 6), a small late response was recorded (Fig. 1) which closely resembled an $\mathrm{F}$ wave (Magladery and McDougal, 1950). Such a late response, already observed in the Holmes-Adie syndrome by Sacco et al. (1978), showed a marked variability and unsteadiness, but was always obtained at a higher threshold than the $M$ response and was constantly facilitated by reinforcement procedures.

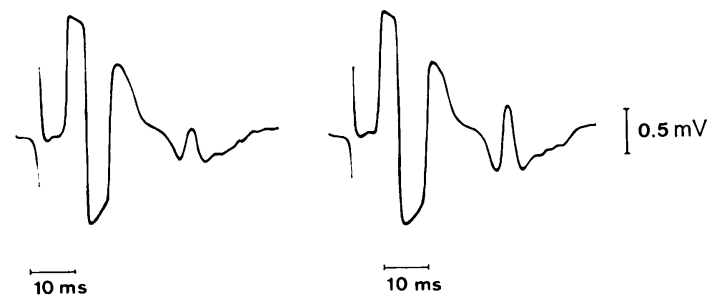

Fig. 1 Response resembling an $F$ wave recorded in a patient with Holmes-Adie syndrome. Left trace: patient relaxed. Right trace: during Jendrassik manoeuvre. Stimulation was supramaximal for $M$ response.

In case 5, an $\mathrm{H}$ response with normal latency and morphology was recorded. The $\mathrm{H} / \mathrm{M}$ ratio was low (0.12), and the recovery cycle turned out to be characterised by a longlasting late depression. The $\mathrm{H}$ reflex could be facilitated by reinforcement manoeuvres.

In all patients vibration of the belly of triceps surae resulted in an enhancement of EMG activity of triceps surae and of the amount of muscle tension developed by plantar flexion of the foot (Fig. 2). The TVR could, therefore, be induced in every subject. Cases 3 and 6 , however, showed TVRs of small size in comparison with the other patients and with normal subjects.

Table Summary of results

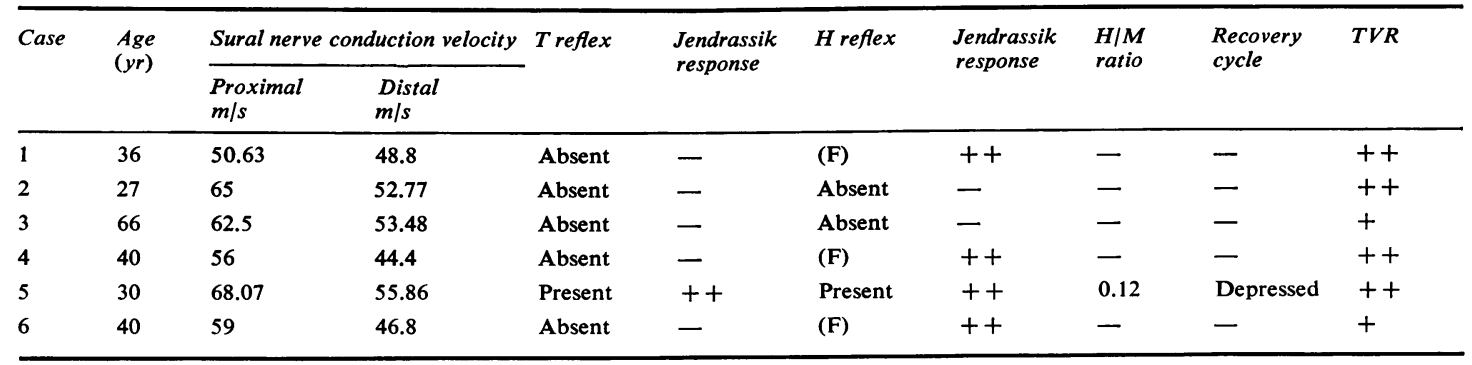




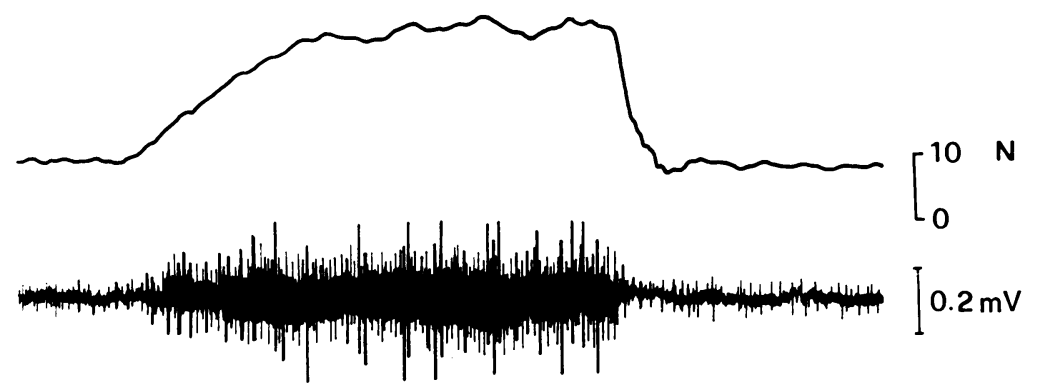

Fig. 2 Example of TVR from a patient with Holmes-Adie syndrome. Upper trace: active torque developed by plantar flexion of the foot, sensed isometrically by force transducer. Lower trace: EMG activity of triceps surae recorded by surface electrodes. Bar indicates vibration period.

\section{$2 s$}

\section{Discussion}

The pathophysiological bases of tendon areflexia in the Holmes-Adie syndrome have been discussed extensively in previous reports. Although even a lesion of diencephalon was suggested (Vogir, 1976), attention has been mainly addressed to different levels in the monosynaptic reflex pathways.

In agreement with the findings of normal motor conduction velocity (Levy, 1967) and nearly normal $\mathrm{H}$ reflex latencies (McComas and Payan, 1966), the evidence of normal sensory impulse conduction in the sural nerve may dismiss the possibility of a peripheral neuropathy.

Involvement of muscle spindles and of the fusimotor system may seem unlikely on account of the normal muscle tone and the positive effect of reinforcement manoeuvres. This evidence is not conclusive, however, since a positive effect of reinforcement manoeuvres is not a reliable proof for the integrity of the fusimotor system (Hagbarth et al., 1975). Nevertheless the presence of TVR in our patients is a strong argument against direct involvement of muscle spindles.

It is well known that mechanical vibration of a muscle belly or tendon produces an involuntary tonic contraction of the vibrated muscle (Hagbarth and Eklund, 1966; Hagbarth, 1973). Although a contribution from skin receptors was recently pointed out (Abbruzzese et al., 1978), the muscle spindle primary endings have been shown to $b=$ the main source of the tonic vibration reflex (Bianconi and Van Der Meulen, 1963; Burke $c t$ al., 1976a, b). The normal development of $\mathrm{TV} R$ may, therefore, be regarded as evidence of integrity of muscle spindles.
McComas and Payan (1966) rejected the possibility of a lesion of alpha-motoneurones as no weakness or impairment of voluntary movements had been shown in the Holmes-Adie syndrome and $M$ waves were of normal latency and amplitude. Further support for this conclusion comes from the presence of TVR with typical time course, which indicates that alpha-motoneurones are recruited normally by vibratory stimuli. Moreover, the late responses observed in three patients of our study resembled the $F$ wave, which is currently regarded as the discharge of spinal motoneurones after antidromic invasion (McLeod and Wray, 1966). Such responses were constantly facilitated by reinforcement, and Sacco et al. (1978) also showed a facilitation after post-tetanic potentiation (cf Hagbarth, 1962). Decrease of excitability of spinal motoneurones (Vanasse et al., 1974) seems, therefore, to be unlikely.

Our findings support the view that the lesion responsible for benign areflexia lies centrally within the spinal cord, possibly involving the Ia presynaptic terminals on the motoneurones (Hardin and Gay, 1965), so that “. . . action potentials from the muscle spindles do reach the cord but fail to produce a response" (McComas and Payan, 1966).

It is not surprising, therefore, that TVR develops normally, as it has been shown that TVR is not only a monosynaptic reflex, but also a polysynaptic reflex (De Gail et al., 1966) with plurisermanal cerrections or long loop comr::.:.:ts (Gillies et al., 1971; Andrews et al., 1973). If a lesion impairing the transmission of impulses from Ia presynaptic terminals to alpha-motoneurones is accepted, it is conceivable that impulses of monosynaptic reflexes ( $T$ and $H$ ) may be 
blocked, whereas impulses of polysynaptic reflexes (TVR) may excite spinal neurones through alternative pathways, even if excitation may sometimes develop to a lesser degree (two cases, in our study, with small TVRs).

A dysfunction of terminals of Ia sensory nerve fibres on spinal motoneurones could also explain the presence of responses resembling $F$ waves: the increasing strength of stimulation could enhance antidromic activation of alpha-motoneurones, usually not observed in normal subjects because of collision between antidromic and orthodromic impulses.

Finally, the longlasting late depression of the $\mathrm{H}$ reflex recovery cycle, as observed in case 5 , could be determined by a reduction of synaptic transmitter (Brooks et al., 1950), as already suggested by McComas and Payan (1966) and Sacco et al. (1978), though an increase of presynaptic inhibition could also be taken into account.

We would like to thank Professor Karl-Erik Hagbarth and Dr Göran Eklund of the Department of Clinical Neurophysiology, Academic Hospital, Uppsala, who reviewed the manuscript and offered helpful suggestions.

\section{References}

Abbruzzese, G., Hagbarth, K.-E., Homma, I., and Wallin, U. (1978). Excitation from skin receptors contributing to the tonic vibration reflex in man. Brain Research, 150, 194-197.

Adie, W. J. (1932). Tonic pupils and absent tendon reflexes, a benign disorder sui generis: its complete and incomplete forms. Brain, 55, 98-113.

Andrews, C., Knowles, L., and Lance, J. W. (1973). Corticoreticulospinal control of the tonic vibration reflex in the cat. Journal of the Neurological Sciences, 18, 207-216.

Behse, F., and Buchthal, F. (1971). Normal sensory conduction in the nerves of the leg in man. Journal of Neurology, Neurosurgery, and Psychiatry, 34, $404-414$.

Bianconi, R., and Van Der Meulen, J. P. (1963). The response to vibration of the end organs of mammalian muscle spindles. Journal of Neurophysiology, 26, 177-190.

Brooks, C. McC., Downman, C. B. B., and Eccles, J. C. (1950). After-potentials and excitability of spinal motoneurones following orthodromic activation. Journal of Neurophysiology, 13, 157-176.

Buchthal, F., and Rosenfalck, A. (1966). Evoked action potentials and conduction velocity in human sensory nerves. Brain Research, 3, 1-122.

Burke, D., Hagbarth, K.-E., Lofstedt, L., and Wallin, B. G. (1976a). The responses of human muscle spindle endings to vibration of non-contracting muscle. Journal of Physiology, 261, 673-693.
Burke, D., Hagbarth, K.-E., Lofstedt, L., and Wallin, B. G. (1976b). The responses of human muscle spindle endings to vibration during isometric contraction. Journal of Physiology, 261, 695-711.

Cameron, M. E. (1959). Lesions of the ciliary ganglion as a cause of Argyll-Robertson and Adie pupils. British Journal of Ophthalmology, 43, 471-476.

De Gail, P., Lance, J., and Neilson, P. D. (1966). Differential effects on tonic and phasic reflex mechanisms produced by vibration of muscle in man. Journal of Neurology, Neurosurgery, and Psychiatry, 29, 1-11.

Gillies, J. D., Burke, D. J., and Lance, J. W. (1971). Supraspinal control of tonic vibration reflex. Journal of Neurophysiology, 34, 302-309.

Hagbarth, K.-E. (1962). Post-tetanic potentiation of myotatic reflexes in man. Journal of Neurology, Neurosurgery, and Psychiatry, 25, 1-10.

Hagbarth, K.-E. (1973). The effect of muscle vibration in normal man and in patients with motor disorders. In New Developments in Electromyography and Clinical Neurophysiology, vol. 3, pp. 428-443. Edited by J. E. Desmedt. Karger: Basel.

Hagbarth, K.-E., and Eklund, G. (1966). Motor effects of vibratory stimuli in man. In Proceedings of First Nobel Symposium, pp. 177-186. Edited by R. Granit. Almqvist and Wiksell: Stockholm.

Hagbarth, K.-E., Wallin, G., Burke, D., and Lofstedt, L. (1975). Effects of the Jendrassik manoeuvre on muscle spindle activity in man. Journal of Neurology, Neurosurgery, and Psychiatry, 38, 1143-1153.

Hardin, W. B., and Gay, A. J. (1965). The phenomenon of benign areflexia. Review of the HolmesAdie syndrome with case reports and study of the Achilles reflex. Neurology (Minneapolis), 15, 613621.

Harriman, D. G. F., and Garland, H. (1968). The pathology of Adie's syndrome. Brain, 91, 401-418.

Holmes, G. (1931). Partial iridoplegia associated with symptoms of other diseases in the nervous system. Transactions of the Ophthalmological Society of the United Kingdom, 51, 209-228.

Hugon, M. (1973). Methodology of the Hoffmann reflex in man. In New Developments in Electromyography and Clinical Neurophysiology, vol. 3, pp. 277-293. Edited by J. E. Desmedt. Karger: Basel.

Levy, R. (1967). The tendon reflexes in the HolmesAdie syndrome. Neurology (Minneapolis), 17, 12131216.

Magladery, J. W., and McDougal, D. B. (1950). Electrophysiological studies of nerve and reflex activity in normal man. I. Identification of certain reflexes in the electromyogram and the conduction velocity of peripheral nerve fibres. Bulletin of the Johns Hopkins Hospital, 86, 255-290.

McComas, A. J., and Payan, J. (1966). Motoneurone excitability in the Holmes-Adie syndrome. In Control and Innervation of Skeletal Muscle, pp. 182193. Edited by B. L. Andrew. Livingstone: Edinburgh. 
McLeod, J. G., and Wray, J. H. (1966). An experimental study of the $\mathrm{F}$ wave in the baboon. Journal of Neurology, Neurosurgery, and Psychiatry, 29, 196-200.

Russell, G. F. M. (1956). The pupillary changes in Holmes-Adie syndrome. Journal of Neurology, Neurosurgery, and Psychiatry, 19, 289-296.

Sacco, G., Pastorino, P., Mantero, M., Ratto, S., and Abbruzzese, M. (1978). Studio neurofisiologico dell'- areflessia benigna. Rivista di Neurologia, 48, 517524.

Vanasse, M., Molina-Negro, P., and Saint-Hilaire, J. M. (1974). Syndrome d'Ádie associé à une hypohidrose segmentaire. Etude clinique et neurophysiologique. Revue Neurologique, 130, 237-244.

Vogir, R. (1976). A propos du syndrome d'Adie. Revue Neurologique, 132, 869-872. 